\title{
Comparison of two established platelet stickiness methods in atherosclerotic patients and normal subjects and a proposed modification
}

\author{
Edwin Besterman, Joan B. Heywood, ${ }^{1}$ and Jillian James ${ }^{2}$ \\ From the Cardiology Department, St. Mary's Hospital, London W.2
}

\begin{abstract}
A fresh evaluation is reported of both Wright and Hellem techniques for measuring platelet stickiness. Reproducibility was better in the Hellem. Nevertheless, the range of results was too wide to demonstrate significant differences between different groups of patients and control subjects. A modification of the Hellem technique has therefore been developed that appears to provide better differentiation.
\end{abstract}

There have been numerous reports of changes in platelet behaviour associated with a range of clinical conditions or after treatment with various drugs. These findings have been reviewed by Hartmann (1968), Hellem (1968), and O'Brien (1969).

The most widely studied aspect of platelets derives from their property of adhesion to glass, usually expressed as 'platelet stickiness'. Wright (I94I) introduced the first simple method to measure this property. Modifications of this and other different methods have been developed subsequently so that results from one laboratory are often not comparable with those obtained elsewhere.

During a study of patients with chronic ischaemic heart disease, using the Wright method, wide fluctuations were found in results from repeated studies on outpatients whose clinical condition was apparently static. These erratic results had been observed by us previously and suggested that a more detailed examination of platelet stickiness techniques

was necessary before any comparisons between either individuals or groups of patients could be made (Besterman, Myat, and Travadi, 1967).

\section{* Investigation of the Wright method}

The results of the study which initially

prompted this investigation had only been ob-

Received 3 June 1970.

1 Research Assistant supported by Boehringer Ingelheim.

${ }^{2}$ Research Technician supported by grant from Joint Standing Research Committee, St. Mary's Hospital. Correspondence to Edwin Besterman, St. Mary's Hospital, London W.2. tained from single tests on each patient. Subsequently duplicate studies were made from I 70 blood samples under carefully controlled conditions; details are shown in Table $I$ and Fig. I. The poor agreement between results from duplicate flasks emphasized the inadequacy of single tests. Numerous variations were then tried in the hope of improving reproducibility: the time of testing the blood after venepuncture was fixed at 15 minutes (Fyfe and Hamilton, 1967); heparin and citrate were both tried as anticoagulant; plastic or siliconed glass tubes were used for the collection of the sample, and an improved method of platelet counting was brought into use. Some of the results from these experiments are summarized in Table $\mathrm{I}$.

Results using the Wright method Despite these various changes in technique there was little improvement in the agreement between results from duplicate tests on the same sample of blood and no evidence that the results distinguished between patients and controls. Therefore it was decided to examine the Hellem (1960) method in a similar manner. This technique, or simple modifications of it, has been used by many workers and found to give repeatable results when conditions were rigidly controlled (O'Brien, I96I; Salzman, 1963; Cronberg, 1967).

\section{Investigation of the Hellem method}

Initially the original Hellem (1960) method was used with only minor changes (see Appendix). 
TABLE I Results from duplicate tests of platelet stickiness on the same blood sample using the various modifications of the Wright and Hellem techniques

\begin{tabular}{|c|c|c|c|c|c|c|c|c|c|}
\hline $\begin{array}{l}\text { Experi- } \\
\text { ment }\end{array}$ & Blood container & & Method & \multicolumn{2}{|c|}{$\begin{array}{l}\text { Time after } \\
\text { venepuncture }\end{array}$} & $\begin{array}{l}\text { No. of } \\
\text { paired } \\
\text { tests }\end{array}$ & $\begin{array}{l}\text { Mean } \\
\text { difference } \\
\text { between } \\
\text { pairs }\end{array}$ & $\begin{array}{l}\text { Range of } \\
\text { difference } \\
\text { between } \\
\text { pairs }(\%)\end{array}$ & $S D$ \\
\hline \multirow{5}{*}{$\begin{array}{l}\text { A } \\
\text { B } \\
\text { C } \\
\text { D } \\
\text { E }\end{array}$} & \multicolumn{2}{|l|}{ Plastic tubes } & Wright & \multirow{2}{*}{\multicolumn{2}{|c|}{$\begin{array}{l}\text { Undefined o-20 min. } \\
\text { Fifteen minutes }\end{array}$}} & 170 & $7 \cdot 1$ & $0-30$ & $6 \cdot 5$ \\
\hline & \multirow{2}{*}{\multicolumn{2}{|c|}{ Siliconed" glass tubes }} & ” & & & 54 & 5.9 & $0-28$ & $5 \cdot 7$ \\
\hline & & & & 川 & , & 23 & $5 \cdot 6$ & $0-17$ & $5 \cdot 3$ \\
\hline & , & " & Hellem & ” & " & 140 & $2 \cdot I$ & $0-12$ & $2 \cdot 0$ \\
\hline & " & ” & Initial stickiness & ”, & " & 81 & 3.4 & $0-13$ & $3 \cdot 1$ \\
\hline
\end{tabular}

Reproducibility Tests were made on 140 samples of blood using duplicate glass bead units and the results are shown in Table $I$. The histogram in Fig. I shows the closer agreement between pairs of results obtained by this method than between those obtained by the Wright method.

Repeatability Among these 140 results, repeated tests over a period on the same patient sometimes showed a sudden change. This was not related to any change in the clinical state of the subject. Results were then compared from 18 subjects, who were tested again after varying intervals (Fig. 2). From this diagram it will be seen that, though there is close agreement between results from some people, others showed considerable differences. These differences had no relation to the intervals between the tests. Bennett (1968) found that the age of the glass bead units influenced the number of platelets removed, more platelets adhering to older units, and as this had not been recognized in the present investigation this might possibly have explained our inconsistent results.

Age of unit Bennett's findings were confirmed using units of differing ages. Some results were conflicting, but on average the older the unit the more platelets were removed, the age effect becoming apparent within five days of the unit being made and appearing to be maximal after 12 to 15 days (Table 2). Subsequently all tests were performed using units which were at least I4 days and less than 4 weeks old.

Differences between groups of patients 'Normal' subjects were asymptomatic volunteers from British Rail; patients with 'acute' cardiac ischaemia were those tested within 24 hours of infarction; those with chronic ischaemic heart disease were outpatients with steady state angina and those with peripheral arterial disease had chronic claudication and arteriographic changes.

The range of results was so wide that no significant mean differences were observed between these four groups (Fig. 3). There was some suggestion within the control group that there might be a slight increase in adhesiveness with age of donor, but as there were few results in each age-group this was not conclusive.

Summary of results obtained by the original Hellem method Thus, despite good reproducibility of the Hellem method from the same sample of blood and improved repeatability from any one individual, the technique failed, in our laboratory, to differentiate satisfactorily between groups of patients and 'control' subjects.

FIG. I Histogram to show range of differences obtained from duplicate samples tested by the Wright, Hellem, and initial stickiness modification of the latter method.

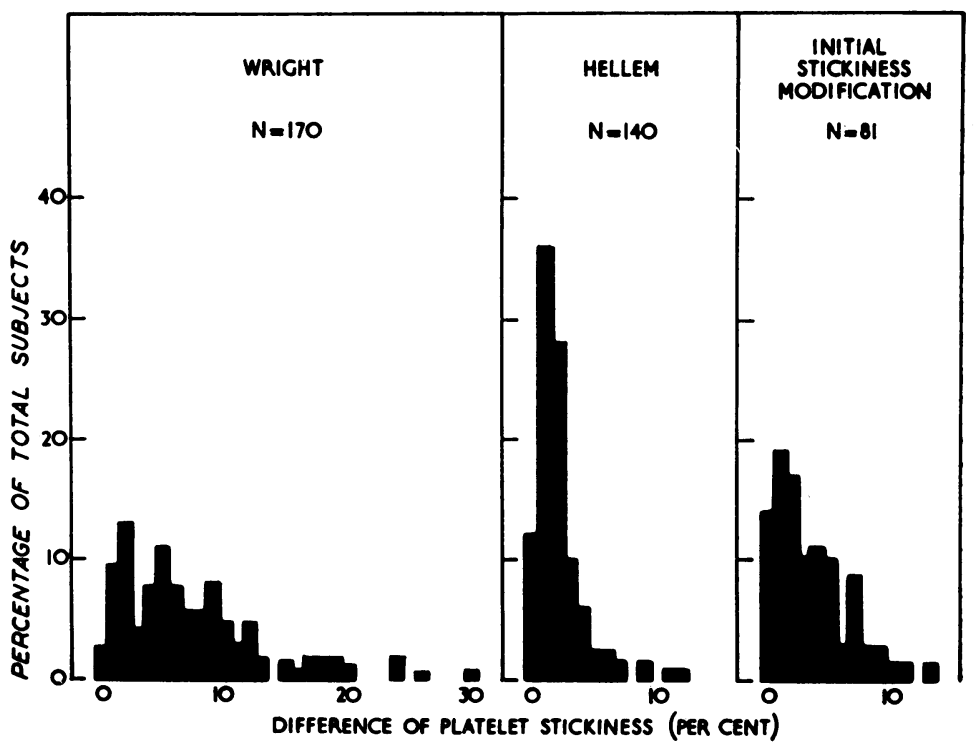




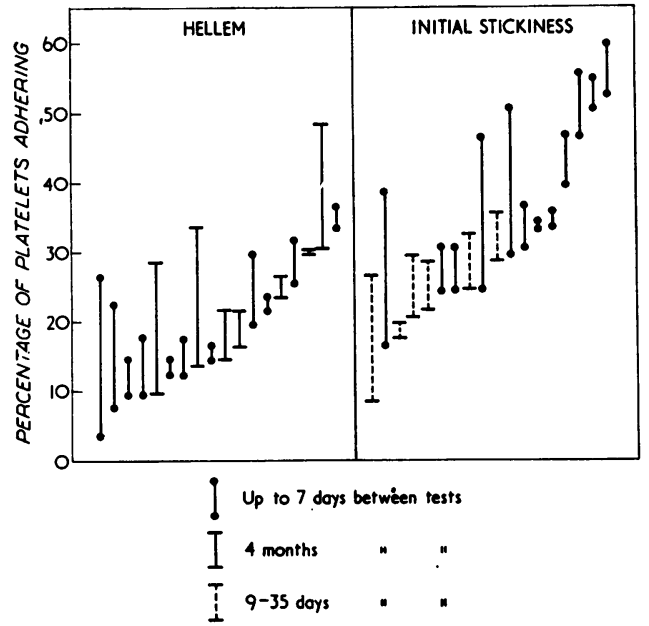

FIG. 2 Range of differences found in serial studies of subjects using Hellem and initial stickiness methods.

\section{Modification of the Hellem technique}

Hellem (1960) and Cronberg (1967) have shown that it is possible to increase the stickiness of a blood sample by either increasing the area of the glass over which it passes or by decreasing the rate of flow. The findings of O'Brien (196I) suggest that under some conditions more platelets are removed from the leading edge of the blood than from subsequent portions of the sample that only touched glass already wetted by blood. It would have been difficult to reduce the rate of flow in the apparatus used in our studies, so changes in the size of the unit and in the amount of blood collected were investigated. Consecutive drops - were collected from both normal and longer length units, and it was found that the first five drops emerging from the unit had the highest percentage of platelets removed.

The final method for the study was deter- mined after a small pilot survey of controls and patients suffering from acute cardiac in-

- farction. This method produced higher results of platelet stickiness in all subjects, the greater increase occurring among the patients. (See Appendix for details of method.) This modification is subsequently referred to as the ' 'initial stickiness' method.

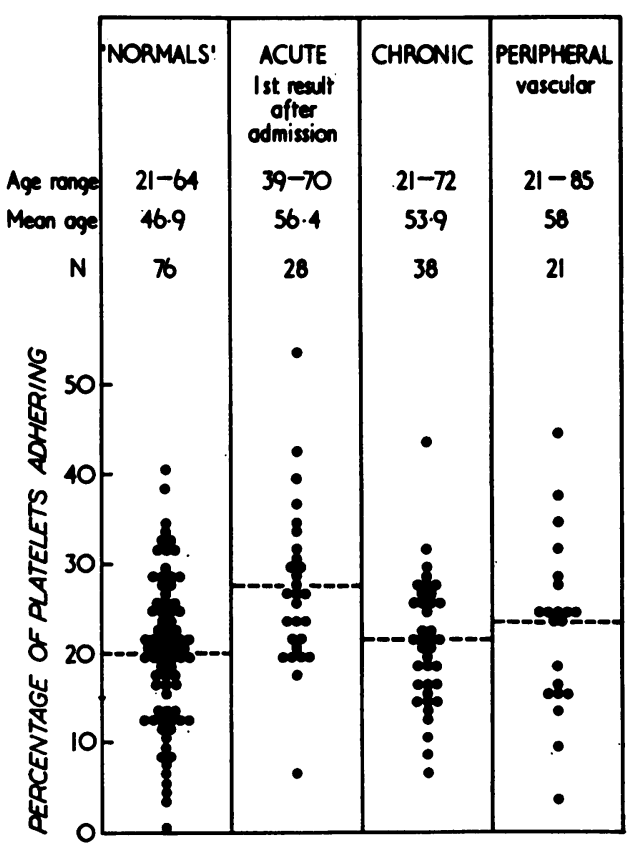

FIG. 3 Range of stickiness using Hellem method in normal subjects and patients suffering from acute infarction, chronic ischaemic heart disease, and peripheral arterial disease.

Investigation of initial stickiness method Reproducibility Duplicate tests were performed on 8I samples of blood and the difference between pairs of results is shown in Fig. I. The agreement was considerably better than that found by the Wright and similar to that obtained by the Hellem method.

Repeatability Repeated tests on 18 subjects performed up to five weeks apart showed close agreement in some cases but a wide difference in four people (Fig. 2). No obvious reasons could be found for these discrepant results. Thirteen other controls tested at weekly intervals for four weeks showed fluctuations which could not be related to either minor illness (colds, eye infection) or to drugs (aspirin). It is obvious, therefore, that a single test on any subject can have no diagnostic significance.

TABLE 2 Increasing stickiness found with increasing age of Hellem glass bead units

\begin{tabular}{llllll}
\hline Age of unit & $0-I$ day & I day-I week & I-2 weeks & $2-3$ weeks & $3-4$ weeks \\
\hline Mean per cent 'stickiness' & $14 \cdot 5$ & $17 \cdot 4$ & $19 \cdot 7$ & $22 \cdot 2$ & $21 \cdot 2$ \\
No. of tests & 35 & 38 & 22 & 13 & 10 \\
\hline
\end{tabular}


Differences between 'normal' control subjects and patients with coronary and peripheral arterial disease From Fig. 4 it can be seen that the results from the individuals within each of the four groups show a wide scatter but both the acute coronary patients and those with peripheral arterial disease have a higher mean figure than a control group, matched for age. In the patients suffering from acute infarction the stickiness was greatest in the first few days and diminished subsequently (Table 3 ). This Table emphasizes the higher values obtained by the initial stickiness method and the bigger differences between results from normal and acute coronary patients.

Relation between stickiness and age of donor Using the Hellem method, there has been a suggestion that stickiness increased with age; this was confirmed with the modified technique (Fig. 5). The mean results from the controls, though few in number in each group, show a slight increase as the mean age of the group rises. This emphasizes the need in all comparisons of platelet stickiness to have age-matched control groups before any findings can be evaluated. Few women were included in any of the groups studied, and the

FIG. 4 Range of stickiness using 'initial stickiness' modification of Hellem method in the same populations as shown in Fig. 3.

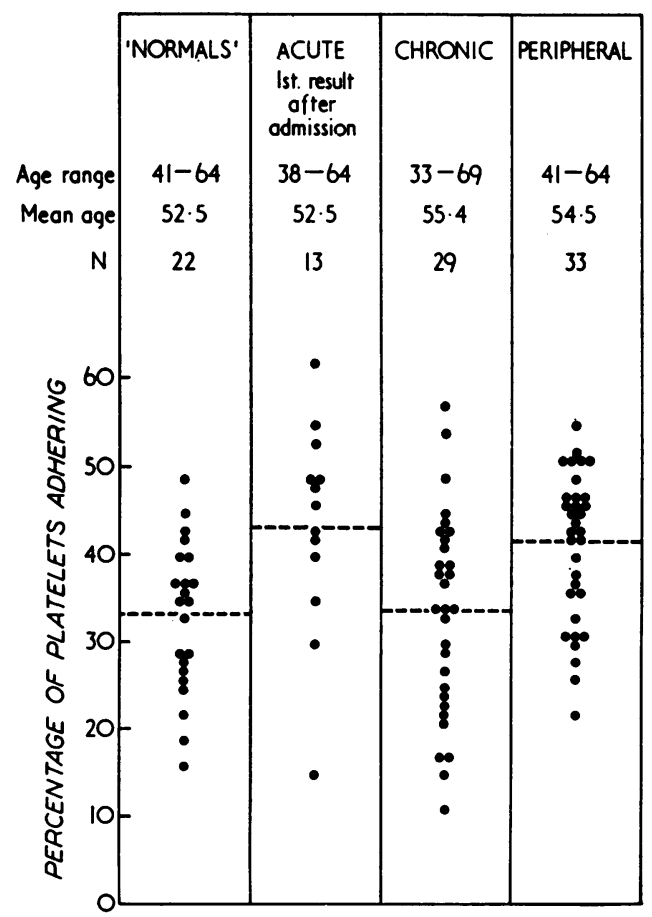

influence of sex on stickiness remains to be investigated.

\section{Discussion}

It was not originally intended to investigate the factors which influence the results in the various platelet methods but only to find one that was both repeatable and would show differences between normal controls and patients.

Several of these methods have recently been evaluated and compared (Hampton, 1967; Hartmann, 1967, I968; Hellem, 1968; Sjögren, Böttiger, and Biörck, 1969). Sjögren et al. found there was good correlation between the results obtained by the Hellem and by the Salzman (1963) whole blood method but weaker correlation with the Wright, and none at all between the Hellem plasma-ADP method (Hellem, Odegaard, and Skålhegg, 1963) and any of the other three. Hirsh, McBride, and Wright (1966) found a close correlation between the Wright method and the Hirsh modification of the Hellem whole blood method. However, few authors have either indicated the reproducibility of the method used or have published details of day-to-day variation in results, either from controls or patients. Hellem (I960) reported monthly tests in one subject over a period of 18 months, and his results ranged from 36 to 68 per cent with a mean value of 50 per cent. Pitney and Potter (1967), using a glass bead column and whole blood, report similar discrepancies between duplicate tests on the same blood sample, and repeated tests on the same individual over three months gave results which varied over the normal range. Some recent reports have failed to confirm earlier claims of significant changes of stickiness either in clinical conditions or after treatment with drugs (Borchgrevink et al., 1965; O'Brien and Heywood, I966; Negus, Pinto, and Brown, I969).

There are obviously disadvantages present in all the techniques and no single method is free from criticism (Hampton, 1967; Hartmann, 1968; Hellem, 1968; Sjögren et al., 1969). The Hellem method appears to have certain advantages when compared with the Wright method in that the glass unit is only used once and no washing is involved; furthermore, no surface has had previous contact with blood.

The finding by Bennett (1968), amply confirmed here, that the age of the glass bead unit has a significant effect on the removal of the platelets is of interest. This may explain some previous work where results were erratic or where poor agreement was obtained between 
TABLE 3 Changing platelet stickiness during the acute phase of cardiac infarction

\begin{tabular}{|c|c|c|c|c|c|c|}
\hline \multirow{3}{*}{$\begin{array}{l}\text { No. of days } \\
\text { after onset }\end{array}$} & \multicolumn{3}{|c|}{ Whole unit method } & \multicolumn{3}{|c|}{ Initial stickiness method } \\
\hline & \multirow{2}{*}{$\begin{array}{l}\text { Mean result } \\
\text { per cent }\end{array}$} & \multicolumn{2}{|c|}{ No. of } & \multirow{2}{*}{$\begin{array}{l}\text { Mean result } \\
\text { per cent }\end{array}$} & \multicolumn{2}{|c|}{ No. of } \\
\hline & & tests & patients & & tests & patients \\
\hline \multirow{5}{*}{$\left.\begin{array}{c}0-2 \\
3-5 \\
6-8 \\
9-14 \\
15-30\end{array}\right\}$} & $26 \cdot 5$ & 47 & 24 & 46 & 18 & 9 \\
\hline & $21 \cdot 6$ & 34 & 24 & $38 \cdot 6$ & $2 I$ & 13 \\
\hline & & & & $35 \cdot 7$ & 20 & II \\
\hline & 20.9 & 47 & 24 & $36 \cdot 2$ & 19 & I0 \\
\hline & $\mathrm{I} 8 \cdot 4$ & 42 & 24 & 30.5 & 23 & 9 \\
\hline 'Normal' values & 20 & & & $33 \cdot 0$ & & \\
\hline
\end{tabular}

duplicate samples. However, it cannot entirely account for erratic serial readings. These remain a notable and disquieting finding in all methods evaluated.

The further modification introduced here of collecting only the first five drops emerging from a longer Hellem type unit was found to give more significant differences between 'populations' than either the Wright or the standard Hellem method. This new method appears to give reliable results in that it is reproducible within \pm 3.5 per cent from the same sample. It must be recognized however, that there may be occasional quite discrepant

FIG. 5 Increasing platelet stickiness with age, using 'initial stickiness' method in 40 control subjects.

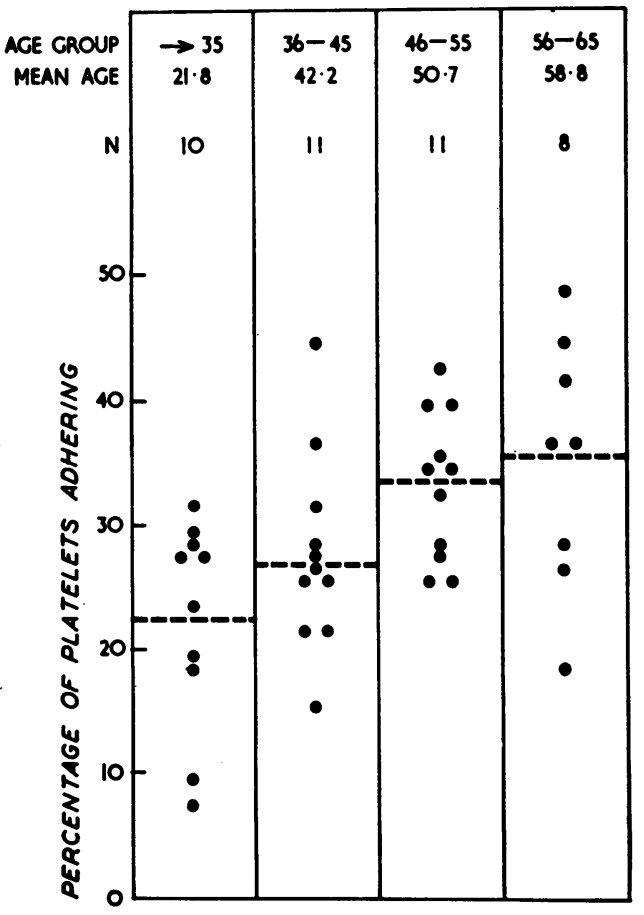

and inexplicable results in a series on any one person. The actual range of values within any group of individuals is large and makes the test useless as a diagnostic method for individual patients. However, the results show that the test may be of use in the evaluation of some specific therapy in a group of patients or in a serial study of individuals suffering from a thrombotic condition. The highest results were found in patients with either widespread peripheral arterial disease or acute infarction rather than in those with chronic coronary disease.

\section{Conclusions}

The present evaluation was made possible by the presence of two skilled and experienced 'platelet counters' (J.H. and J.J.). This permitted extensive cross checking and duplicate analyses, not previously possible in our laboratory. From the results the following conclusions and suggestions can be made:

The Hellem technique has fewer sources of potential error and is more reproducible than the Wright.

The 'initial stickiness' modification of the Hellem method increases the differences found between certain clinical conditions.

Counting errors are reduced by the use of procaine in the diluent.

Alterations in stickiness occur with ageing of the glass bead unit (as first noted by Bennett, I968).

In a 'normal' male population, increasing stickiness occurs with age.

In patients, isolated results are probably valueless. However, serial studies in subjects may be meaningful, for example, in acute changing states (as shown by patients recovering from acute cardiac infarction) and in patients on therapy specifically influencing platelet behaviour, such as dipyridamole or aspirin (such studies are now being carried out). 


\section{Appendix}

Wright The method was essentially that of the McDonald and Edgill (1959) modification of the original technique.

Hellem The technique was similar to that originally used but substituting $3 \cdot 2$ per cent citrate for 3.8 per cent. The glass bead unit consisted of $2.5 \mathrm{~g}$. washed glass ballotini (Jencons No. 8) in $7.5 \mathrm{~cm}$. lengths of ESCO polythene tubing, internal bore 3/16 in. The ballotini were held in position between layers of nylon mesh, which in turn were held by narrower tubing. The blood was tested 15 minutes after venepuncture. About $3 \mathrm{ml}$. of blood was taken up into narrow plastic tubing and the ends of the tubing clamped. One end was connected to a mechanically driven syringe containing liquid paraffin and the other end to the glass bead unit. The clamps were removed and the blood pushed through the unit. The syringe was driven at such a speed that the transit time through the unit was 23 seconds and $\mathrm{r} \cdot 8 \mathrm{ml}$. of blood was collected in 47 seconds. The sample was collected into a siliconed container. The apparatus was such that up to four syringes could be driven simultaneously at the same speed. This allowed either different samples or repeats from the same sample to be tested at exactly the same time.

Initial stickiness modification A glass bead unit containing $3.75 \mathrm{~g}$. of ballotini was used in a tube $13 \mathrm{~cm}$. long and only the first five drops emerging from the unit were collected on a piece of Parafilm. From this pooled blood the final platelet counts were taken.

Platelet-counting methods Originally the solution of Brecher and Cronkite (r950) was used and only single counts made on each dilution. Later an alternative diluent (Feissly and Lüdin, 1949) containing cocaine to sphere the platelets was found to be preferable. A further change followed when it was found that procaine was as effective a sphering agent.

Calculation of results Wright originally expressed her results by calculating the final count as a percentage of the initial count - that is, a low figure indicated a high level of stickiness. This led to much confusion in the discussion of the results, as most other workers calculated the stickiness in the more logical manner, expressing the difference between the initial and final counts (the number of platelets removed) as a percentage of the initial count. This latter method is used for the calculation of all results in this work.

\section{References}

Bennett, P. N. (1968). Observations on the measurement of platelet adhesiveness with the glass bead column technique. Scandinavian fournal of Haematology, 5, 428 .
Besterman, E., Myat, G., and Travadi, V. (1967). Diurnal variations of platelet stickiness compared with effects produced by adrenaline. British Medical fournal, 1, 597.

Borchgrevink, C. F., Berg, K. J., Skaga, E., Skjaeggestad, Ø., and Stormorken, H. (1965). Effect of linseed oil on platelet adhesiveness and bleedingtime in patients with coronary heart-disease. Lancet, 2, 980.

Brecher, G., and Cronkite, E. P. (1950). Morphology and enumeration of human blood platelets. fournal of Applied Physiology, 3, 365.

Cronberg, S. (1967). Methodological problems in testing of platelet adhesiveness. Scandinavian fournal of Haematology, 4, 385.

Feissly, R., and Lüdin, H. (1949). Microscopie par contrastes de phases (III. Applications à l'hématologie). Revue d'Hématologie, 4, 48I.

Fyfe, T., and Hamilton, E. (1967). Effect of variation of the interval between venepuncture and measurement of platelet adhesiveness by the Payling Wright method. Lancet, 2, 542.

Hampton, J. R. (1967). The study of platelet behaviour and its relevance to thrombosis. Fournal of Atherosclerosis Research, 7, 729.

Hartmann, R. C. (1967). Platelet adhesiveness: the retention of platelets on glass surfaces. Thrombosis et Diathesis Haemorrhagica, Suppl. 26, p. 281.

- (1968). Tests of platelet adhesiveness and their clinical significance. Seminars in Hematology, $5,60$.

Hellem, A. J. (1960). The adhesiveness of human blood platelets in vitro. Scandinavian fournal of Clinical and Laboratory Investigation, 12, Suppl. 51.

- (1968). Platelet adhesiveness. Series Haematologica, n.s. $x$, no. 2, p. 99.

—, Ödegaard, A. E., and Skålhegg, B. A. (1963). Investigations on adenosine diphosphate (ADP) induced platelet adhesiveness in vitro. Part $\mathrm{I}$. The ADP-platelet reaction in various experimental conditions. Thrombosis et Diathesis Haemorrhagica, 10, 61.

Hirsh, J., McBride, J. A., and Wright, H. P. (1966). Platelet adhesiveness: a comparison of the rotating bulb and glass-bead column methods. Thrombosis et Diathesis Haemorrhagica, 16, 100.

McDonald, L., and Edgill, M. (1959). Changes in coagulability of the blood during various phases of ischaemic heart-disease. Lancet, 1 , I I I 5.

Negus, D., Pinto, D. J., and Brown N. (1969). Platelet adhesiveness in postoperative deep-vein thrombosis. Lancet, I, 220.

O'Brien, J. R. (I96I). The adhesiveness of native platelets and its prevention. Fournal of Clinical Pathology, 14, 140 .

- (1969). Platelet aggregation tests and thrombosis. fournal of the Royal College of Physicians of London, 3, 193.

3, and Heywood, J. B. (1966). A comparison of platelet stickiness tests during an Atromid-S trial. Thrombosis et Diathesis Haemorrhagica, 16, 768.

Pitney, W. R., and Potter, M. (1967). Retention of platelets by glass bead filters. Fournal of Clinical Pathology, 20, 7 10.

Salzman, E. W. (1963). Measurement of platelet adhesiveness. Fournal of Laboratory and Clinical Medicine, 62, 724.

Sjögren, A., Böttiger, L. E., and Biörck, G. (1969). Platelet adhesion: a comparison of four methods. Acta Medica Scandinavica, 185, 127.

Wright, H. P. (194I). The adhesiveness of blood platelets in normal subjects with varying concentrations of anti-coagulants. Fournal of Pathology and Bacteriology, 53, 255. 